\title{
Clinical course and outcomes of type-2 diabetic patients after treatment intensification for insufficient glycaemic control - results of the 2 year prospective DiaRegis follow-up
}

Peter Bramlage ${ }^{1 *}$, Anselm K Gitt ${ }^{2,3^{*}}$, Steffen Schneider ${ }^{2}$, Evelin Deeg ${ }^{2}$, Diethelm Tschöpe ${ }^{4,5}$ and for the DiaRegis Study Group

\begin{abstract}
Background: In cases where antidiabetic monotherapy is unable to sufficiently control glucose levels in patients with type-2 diabetes, treatment needs to be intensified. Determining factors that may be predictors for the occurrence of comorbidities in these patients is essential for improving the efficacy of clinical diabetes care.

Methods: The DiaRegis prospective cohort study included 3,810 type-2 diabetics for whom the treating physician aimed to intensify and optimise antidiabetic treatment due to insufficient glucose control. Treatment intensification was defined as increasing the dose of the originally prescribed drug, and/or selecting an alternative drug, and/or prescribing an additional drug. The aims were to monitor the co-morbidity burden of type-2 diabetic patients over a follow-up of two years, and to identify multivariable adjusted predictors for the development of comorbidity and cardiovascular events.
\end{abstract}

Results: A total of 3,058 patients completed the 2 year follow-up. A substantial proportion of these patients had co-morbidities such as vascular disease, neuropathy, and heart failure at baseline. After treatment intensification, there was an increased use of DPP-4 inhibitors, insulin, and GLP-1 analogues, achieving reductions in HbA1c, fasting plasma glucose, and postprandial glucose. During the 2 year period $2.5 \%$ of patients $(n=75)$ died, $3.2 \%$ experienced non-fatal macrovascular events, $11.9 \%$ experienced microvascular events, and $4.3 \%$ suffered onset of heart failure. Predictors for combined macro-/microvascular complications/heart failure/death were found to be age (OR 1.36; $95 \% \mathrm{Cl} 1.10-1.68)$, prior vascular disease (1.73; 1.39-2.16), and history of heart failure (2.78; 2.10-3.68).

Conclusions: Determining the factors that contribute to co-morbidities during intensive glucose-lowering treatment is essential for improving the efficacy of diabetes care. Our results indicate that age, prior vascular disease, and heart failure constitute important predictors of poor cardiovascular outcomes in patients receiving such therapy.

Keywords: Diabetes type 2, Glucose control, Co-morbidities, Treatment intensification, Oral antidiabetic drug, Macrovascular, Microvascular, Heart failure

\footnotetext{
* Correspondence: peter.bramlage@ippmed.de; gitta@klilu.de

${ }^{1}$ Institut für Pharmakologie und präventive Medizin, Menzelstrasse 21, 15831

Mahlow, Germany

${ }^{2}$ Institut für Herzinfarktforschung Ludwigshafen, Ludwigshafen, Germany

Full list of author information is available at the end of the article
} 


\section{Background}

Monotherapy with antidiabetic drugs such as metformin is the first choice treatment strategy for type-2 diabetics for whom dietary restrictions have not managed to achieve adequate control of the condition [1-3]. Treatment escalation is left to the discretion of the consulting physician, with a variety of options available, including changes in the drug being administered or prescribing additional oral antidiabetic drugs (OADs). Injectable drugs such as GLP1 analogues or insulin are considered to be second line alternatives. Insulin is usually recommended only when HbA1c values remain high; however, recent data have suggested that it may be safe when added earlier in the treatment process [4].

Any treatment decision should consider the patient's particular characteristics and specific treatment goals, as well as the economic aspects [5]. This approach, however, diminishes the utility of pre-defined treatment goals and drug selection algorithms, instead favouring a treatment strategy that meets the needs of individual patients. In this regard, the European Association for the Study of Diabetes (EASD) in partnership with the American Diabetes Association (ADA) [3] and the European Society of Cardiology (ESC) [6] have provided guidelines for more patient-centred care strategies for type-2 diabetics. These guidelines are less prescriptive than prior algorithms, and owing to the lack of evidence-based inferences, their ultimate value will only become clear with comparative studies that assess real-world outcomes.

The DiaRegis prospective cohort study was designed to include patients where the treating physician aimed to intensify and optimise antidiabetic treatment due to insufficient glucose control [7]. The patients included were being treated with either one or two oral antidiabetic drugs at the time of enrolment. Treatment intensification was defined as increasing the dose of the originally prescribed drug, and/or selecting an alternative drug, and/or prescribing an additional drug. Against this background, the aim of our analysis was 1) to monitor the co-morbidity burden of type-2 diabetic patients over a follow-up of two years, and 2) to identify multivariable adjusted predictors for the development of co-morbidity and cardiovascular events.

\section{Methods}

DiaRegis is a prospective, observational, multicentre cohort study (registry) that included 3,810 patients with type-2 diabetes under the auspices of the foundation "Der herzkranke Diabetiker" in Germany. It was conducted in accordance with Good Epidemiology Practice (GEP), and applicable regulatory requirements. The protocol was approved by the ethics committee of the Landesärztekammer Thüringen in Jena, Germany on March $4^{\text {th }} 2009$, and published at baseline [7]. All patients enrolled in this registry provided written informed consent.

\section{Patients}

Patients were enrolled in the DiaRegis registry on a consecutive basis, the mean recruitment per physician office being 13 consecutive eligible patients. At the time of enrolment, they were being treated with either one or two oral antidiabetic drugs, with the treating physician wishing to intensify treatment at the baseline visit due to inadequate glycaemic control. Such intensification included initiating an increase in the dose of the originally prescribed drug, and/or selecting an alternative drug, and/or prescribing an additional drug. Any change in treatment was left to the discretion of the treating physician without any leverage due to the study protocol.

Patients without treatment intensification or those being administered injectable antidiabetic drugs prior to baseline were not considered eligible. Further exclusion criteria included the following: patient not under regular supervision of the treating physician for the duration of the study, type-1 diabetes, pregnancy, diabetes secondary to malnutrition, infection or surgery, maturity onset diabetes of the young, known cancer or limited life expectancy, acute emergencies, participation in a separate clinical trial, and other factors preventing the patient from participating in the follow-up appointments (language skills, disabilities, hospitalisation). Patients were followed for a total of 24 months.

\section{Physicians}

Physicians (general practitioners, internists, practitioners, and diabetologists) were selected based on a conditioned random sampling method. A physician database containing approximately 9,350 office-based physicians currently treating patients with type- 2 diabetes were approached in writing. Physicians randomly distributed across all German regions with at least 150 patients with type 2 diabetes under regular medical care were invited to participate. This resulted in 313 participating physicians, representing $3.3 \%$ of the initially approached sample.

\section{Documentation}

Patient data were entered via a secure website directly into an electronic database maintained at the Institut für Herzinfarktforschung, Ludwigshafen, Germany. This enabled online checking for plausibility and completeness. A summary of the data collected in DiaRegis, in addition to further details regarding monitoring of the collection, is provided in the design and baseline publication [7]. All data sets were included in the subsequent statistical analysis.

\section{Glucose control, hypoglycaemia, and co-morbidity}

HbA1c, fasting glucose (overnight), and postprandial glucose ( $2 \mathrm{~h}$ after the last meal) levels were recorded at each of the follow-up visits. They were either measured 
in the physician's office or recorded in specific patient diaries. No further validation or standardisation of values was attempted due to the real world-design, in addition to logistical reasons.

Data on co-morbid disease conditions and risk factors were reported by the treating physician; diagnoses were not verified independently. Crude hypoglycaemia rates were reported for history of prior hypoglycaemia (any recalled hypoglycaemia within the last 12 months) and incident hypoglycaemia (new episodes of hypoglycaemia within the 2 year follow-up). Vascular disease included coronary artery disease (CAD), stroke/transient ischaemic attack (TIA), and peripheral artery disease (PAD). Macrovascular complications included new MI, stroke, and PAD (requiring any peripheral intervention). Microvascular complications included previously unknown retinopathy, nephropathy, neuropathy, and amputation.

\section{Statistical analysis}

The statistical analyses were performed using SAS, version 9.3 (Cary, North Carolina, USA). The distribution of continuous variables is described with medians and quartiles. Categorical parameters are presented as percentages and absolute numbers. All descriptive statistics are based on available cases. The adjusted prognostic value of patient characteristics, laboratory values at baseline, and co-morbidities on different events during the follow-up period were investigated through logistic regression analyses. The resulting odds ratios (ORs) are presented with corresponding 95\% confidence intervals (CIs).

\section{Results}

A total of 3,810 patients were included in the DiaRegis registry (Figure 1). Out of the 3,058 patients that completed the 2 year follow-up period $(80.3 \%$ of those enrolled), $2.5 \%$ had died ( $\mathrm{n}=75$ ). The patients that did not complete the follow-up did not display significantly different baseline characteristics, laboratory values, comorbidities, or pharmacotherapies to those that did complete the study (data not shown).

\section{Patient characteristics}

Patients with a complete two-year follow-up had a median age of $66.1(57.7-72.9)$ years, $46.7 \%$ were female, the median bodyweight was $88 \mathrm{~kg}(78-100)$, and the median duration of diabetes was 5.6 years $(2.9-9.4)$ at baseline (Table 1). Median HbA1c was $7.4 \%$ (6.8-8.2), fasting plasma glucose was141 $\mathrm{mg} / \mathrm{dL}$ (119-169) and postprandial plasma glucose was $183 \mathrm{mg} / \mathrm{dL}$ (155-220). Within the 12 months prior to inclusion into DiaRegis, $1.4 \%$ of patients had experienced an episode of severe hypoglycaemia. A substantial proportion of patients (24.3\%) had known vascular disease with CAD and/or prior stroke or TIA and/or PAD). Furthermore, 14.5\% had

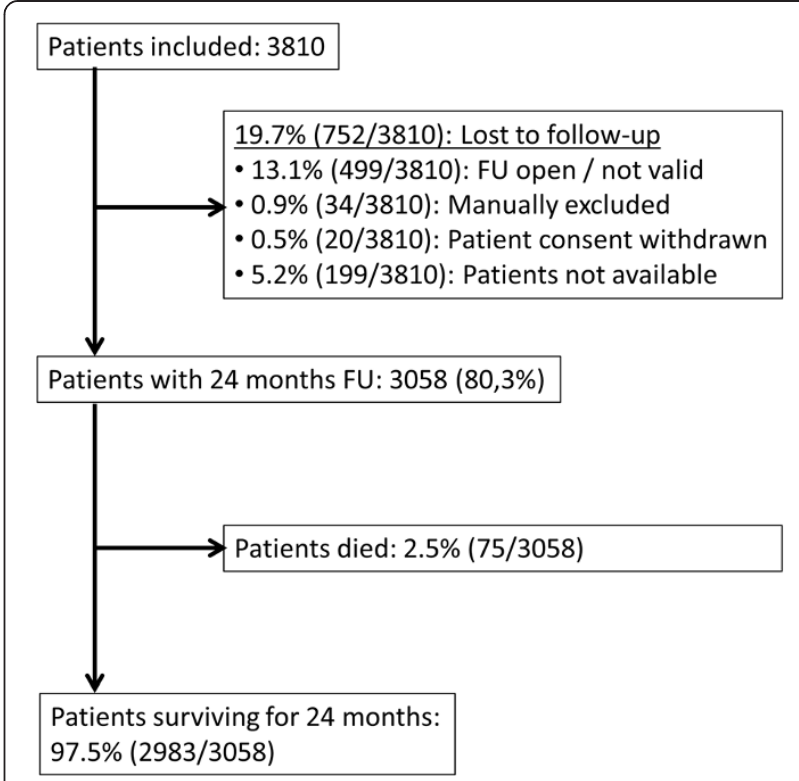

Figure 1 Patient flow chart.

known autonomic or peripheral neuropathy and 9.9\% had prior heart failure (HF).

\section{Pharmacotherapy and the course of glucose control}

As per the protocol, patients were receiving either monoor dual combination oral antidiabetic treatment at the time of enrolment. There was a predominance of oral monotherapy $(68.2 \%)$ at this point, with many of these patients being switched to combination therapies (dual OAD 50.0\%; triple OAD 7.9\%) at the baseline visit (Figure 2, upper graph). This was accompanied by a significant increase in prescription of DPP-4 inhibitors (4.8\% v 39.3\%), insulin (0\% v 17.6\%), and GLP-1 analogues (0\% v 6.90\%) (Figure 2, lower graph). After the initial adaptation of therapy at baseline, additional changes in pharmacotherapy were moderate, with a gradual further increase in insulin use (up to $25.2 \%$ at 2 years) and a decline in dual oral combinations (50.0\% after baseline visit down to $41.5 \%$ at 2 years).

The treatment switch at baseline resulted in a considerable reduction in median HbA1c levels (7.4\% to $6.9 \%$ ), fasting plasma glucose $(140.8 \mathrm{mg} / \mathrm{dL}$ to $123.0 \mathrm{mg} / \mathrm{dL})$, and postprandial glucose $(183.0 \mathrm{mg} / \mathrm{dL}$ to $159.5 \mathrm{mg} / \mathrm{dL})$ in the first 6 months of the follow-up period (Figure 3). These values were found to be relatively stable through to the final follow-up visit at 2 years. The median body weight $(88 \mathrm{~kg})$ in the overall population was stable throughout the 2 year period.

\section{Adverse event burden of type-2 diabetic patients over the two year follow-up}

During the 2 year follow-up period, 75 patients $(2.5 \%)$ died. A further $3.2 \%$ experienced a macrovascular event, 
Table 1 Patient characteristics at baseline

\begin{tabular}{|c|c|c|}
\hline & $\begin{array}{l}\text { Patients included } \\
(\mathrm{n}=3810)\end{array}$ & $\begin{array}{c}\text { Patients with a } 2 \text { year } \\
\mathrm{FU}^{*}(\mathrm{n}=3058)\end{array}$ \\
\hline Age (years) & $65.9(57.6-72.9)$ & $66.1(57.7-72.9)$ \\
\hline Female gender (\%) & 46.7 & 46.7 \\
\hline Body weight (kg) & $88(78-100)$ & $88(78-100)$ \\
\hline Diabetes duration (years) & $5.5(2.9-9.4)$ & $5.6(2.9-9.4)$ \\
\hline \multicolumn{3}{|l|}{ Lipid values } \\
\hline $\mathrm{LDL}-\mathrm{C}(\mathrm{mg} / \mathrm{dL})$ & $120(98-145)$ & $119(96-145)$ \\
\hline $\mathrm{HDL}-\mathrm{C}(\mathrm{mg} / \mathrm{dL})$ & $47(40-57)$ & $47(40-56)$ \\
\hline $\mathrm{TG}(\mathrm{mg} / \mathrm{dL})$ & $176(127-242)$ & $175(127-241)$ \\
\hline $\mathrm{TC}(\mathrm{mg} / \mathrm{dL})$ & $204(175-232)$ & $211(181-235)$ \\
\hline Blood pressure $(\mathrm{mmHg})$ & $137 / 80$ & $137 / 80$ \\
\hline \multicolumn{3}{|l|}{ Blood glucose } \\
\hline $\mathrm{HbA1c}(\%)$ & $7.4(6.8-8.3)$ & $7.4(6.8-8.2)$ \\
\hline $\mathrm{FPG}(\mathrm{mg} / \mathrm{dL})$ & $142(119-171)$ & 141 (119-169) \\
\hline PPG (mg/dL) & $185(155-221)$ & $183(155-220)$ \\
\hline $\begin{array}{l}\text { Hypoglycaemia requiring } \\
\text { assistance (\%) }\end{array}$ & 1.2 & 1.4 \\
\hline \multicolumn{3}{|l|}{ Concomitant disease (\%) } \\
\hline Prior MI (\%) & 6.0 & 5.8 \\
\hline Prior stroke/TIA (\%) & 4.6 & 4.8 \\
\hline HF (\%) & 9.9 & 9.9 \\
\hline PAD (\%) & 6.0 & 6.2 \\
\hline Prior amputation (\%) & 0.9 & 0.9 \\
\hline Any neuropathy (\%) & 15.9 & 14.5 \\
\hline Any retinopathy (\%) & 4.2 & 4.2 \\
\hline Vascular disease $(\%)^{* *}$ & 24.0 & 24.3 \\
\hline \multicolumn{3}{|l|}{$\begin{array}{l}\text { Cardiovascular } \\
\text { pharmacotherapy }\end{array}$} \\
\hline ACEi & 50.0 & 50.5 \\
\hline ARB & 21.8 & 21.9 \\
\hline Betablocker & 46.6 & 46.5 \\
\hline CCB & 24.9 & 25.4 \\
\hline Diuretic & 41.2 & 42.0 \\
\hline ASA & 33.6 & 33.8 \\
\hline Statin & 42.2 & 42.6 \\
\hline \multicolumn{3}{|l|}{$\begin{array}{l}\text { Antidiabetic therapy } \\
\text { post baseline }\end{array}$} \\
\hline Metformin (\%) & 84.5 & 84.5 \\
\hline Sulfonylureas (\%) & 26.2 & 27.2 \\
\hline $\begin{array}{l}\text { Glucosidase } \\
\text { inhibitors (\%) }\end{array}$ & 2.3 & 2.6 \\
\hline Glinides (\%) & 6.0 & 5.3 \\
\hline DPP-4 inhibitors (\%) & 38.8 & 39.3 \\
\hline
\end{tabular}

Table 1 Patient characteristics at baseline (Continued)

\begin{tabular}{lcc}
\hline Glitazones (\%) & 10.3 & 10.1 \\
GLP-1 analogues (\%) & 9.2 & 9.7 \\
Insulin (\%) & 17.3 & 17.6 \\
\hline Legend: *Including those that died during follow-up; **vascular disease \\
includes CAD, prior stroke/TIA, and/or PAD; FU, follow-up; TG, triglycerides; \\
FPG, fasting plasma glucose; PPG, postprandial plasma glucose; MI, myocardial \\
infarction; TIA, transitory ischemic attack; HF, heart failure; PAD, peripheral \\
artery disease; ACEi, angiotensin-converting enzyme inhibitor; ARB, angiotensin \\
receptor blocker; CCB, calcium channel blocker; ASA, acetylsalicylic acid; DPP, \\
dipeptidylpeptidase; GLP, glucagon-like peptide; SU, sulfonylurea. \\
\\
defined as CAD, stroke/TIA, or PAD (Table 2). Micro- \\
vascular complications were more frequent (11.9\%). Inci- \\
dent HF was reported in 4.3\% of the patients during the \\
2-year follow up.
\end{tabular}

Multivariable adjusted predictors for the development of comorbidity and vascular events

We identified multivariable adjusted predictors for macro- and microvascular events, as well as HF (Table 3). There was a consistent trend towards increased event rates in patients with prior vascular disease, HF, and longer diabetes duration. Predictors for the combined endpoint (macro-/microvascular complication/HF/death) were age (OR 1.36; 95\% CI 1.10-1.68), prior vascular disease $(1.73 ; 1.39-2.16)$, and history of prior HF (2.78; 2.10-3.68).

Particularly noteworthy were the increased risk for macrovascular events in patients with a diabetes duration of at least 5.6 years (median; OR 1.94; 95\% CI 1.24-3.05) and the increased risk of HF in the elderly (OR 2.25; 95\% CI 1.21-4.16).

\section{Discussion}

In the present study, we monitored type- 2 diabetes patients for 2 years after intensification of their antidiabetic treatment, in order to identify comorbidities and risk factors that might be associated with poor outcome. At baseline, glycaemic control after being treated with either one or two OADs was considered to be insufficient. Therefore, upon enrolment into this study, patients were commonly switched to combination therapies, which often included the use of DPP-4 inhibitors, insulin, and GLP-1 analogues. We observed that these intensified regimens were typically accompanied by a significant reduction in median HbA1c levels. However, patients continued to exhibit considerable risk for death $(2.5 \%)$, macrovascular complications (3.2\%), microvascular complications (11.9\%), and HF (4.3\%).

Although cardiovascular co-morbidities associated with diabetes treatment were identified, it should be noted that a substantial proportion of patients had known vascular disease $(24.3 \%)$ or $\operatorname{HF}$ (9.9\%; any severity) at baseline. Nevertheless, we observed a considerable burden of incident comorbidities, which is in good agreement with 


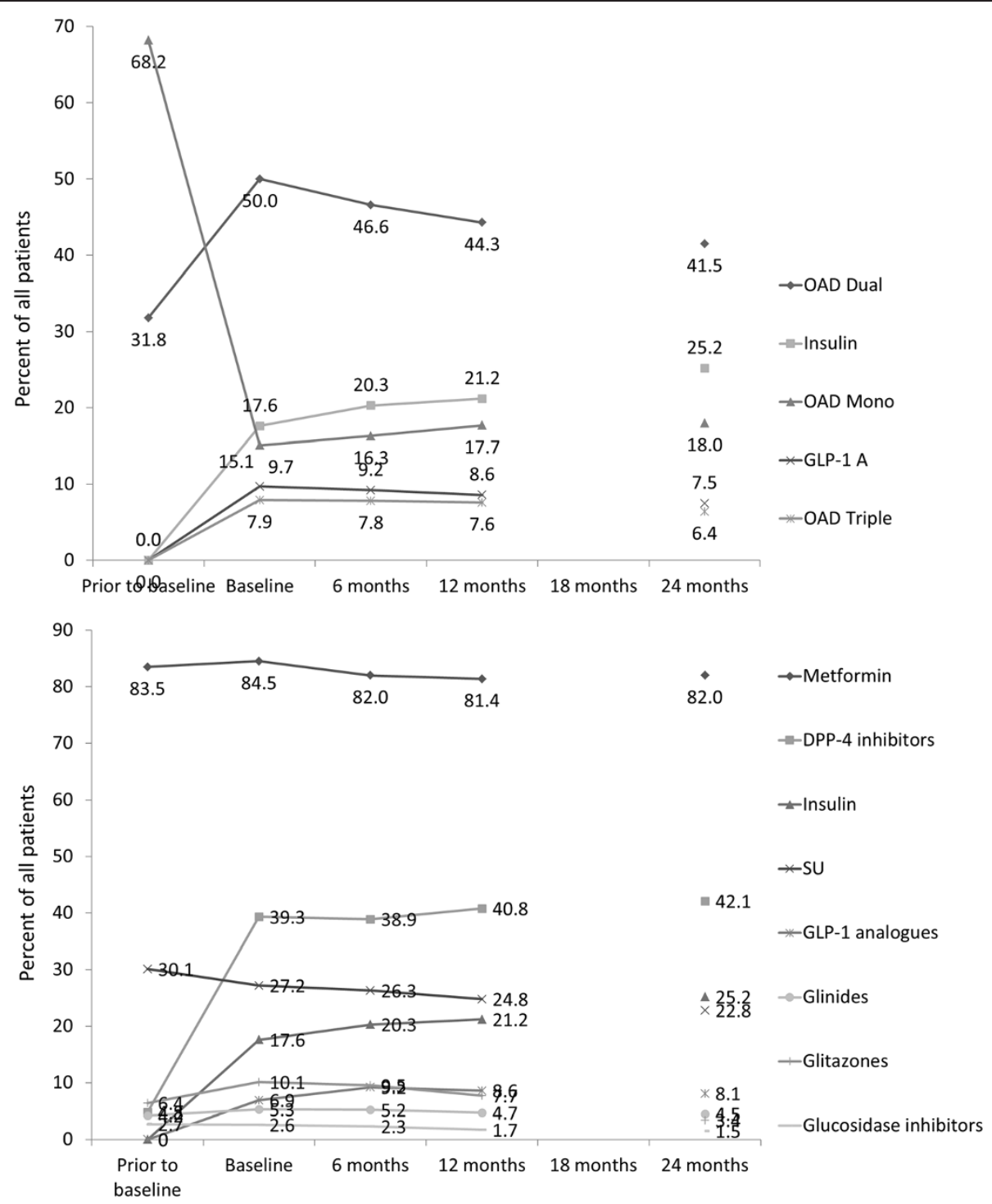

Figure 2 Change in therapy during follow-up period. Upper graph: Combinations of OADs, insulin, and GLP-1 analogues; Lower graph: differences in treatment therapies.

previous observations. While there are many studies demonstrating a link between diabetes and increased cardiovascular risk, there is also evidence of an association with death from other causes. A study by Gordon-Dseagu et al. found that mortality due to respiratory disease or some cancers was greater in diabetic patients [8]. Furthermore, a recent analysis of 820,900 patients included in prospective studies demonstrated increased overall mortality in patients with diabetes, in addition to increases in death from a variety of cancers, vascular causes, renal disease, and other factors [9]. There is the possibility that differences in these risks originate not only from dysglycaemia, but also from the particular treatment strategy selected. For example, a number of antidiabetic drugs, including insulin, have been linked to weight gain [10], and there is an ongoing debate regarding the safety of certain drugs such as sulfonylureas [11], resulting in an FDA request for macrovascular endpoint studies. Two such studies, the EXAMINE and SAVOR TIMI-53 trials [12,13], demonstrated no increased risk with gliptin use. This was in agreement with a meta-analysis by Gooßen et al., who reported few associations between risk and gliptin monotherapy; the data regarding combination therapies were less clear however [14]. Therefore, it appears that further in depth study is required in order to delineate which patient characteristics or drug types contribute to the observed variability in cardiovascular risk during intensified treatment strategies.

With regard to risk factors that might predict a poor cardiovascular outcome during intensified treatment, we 


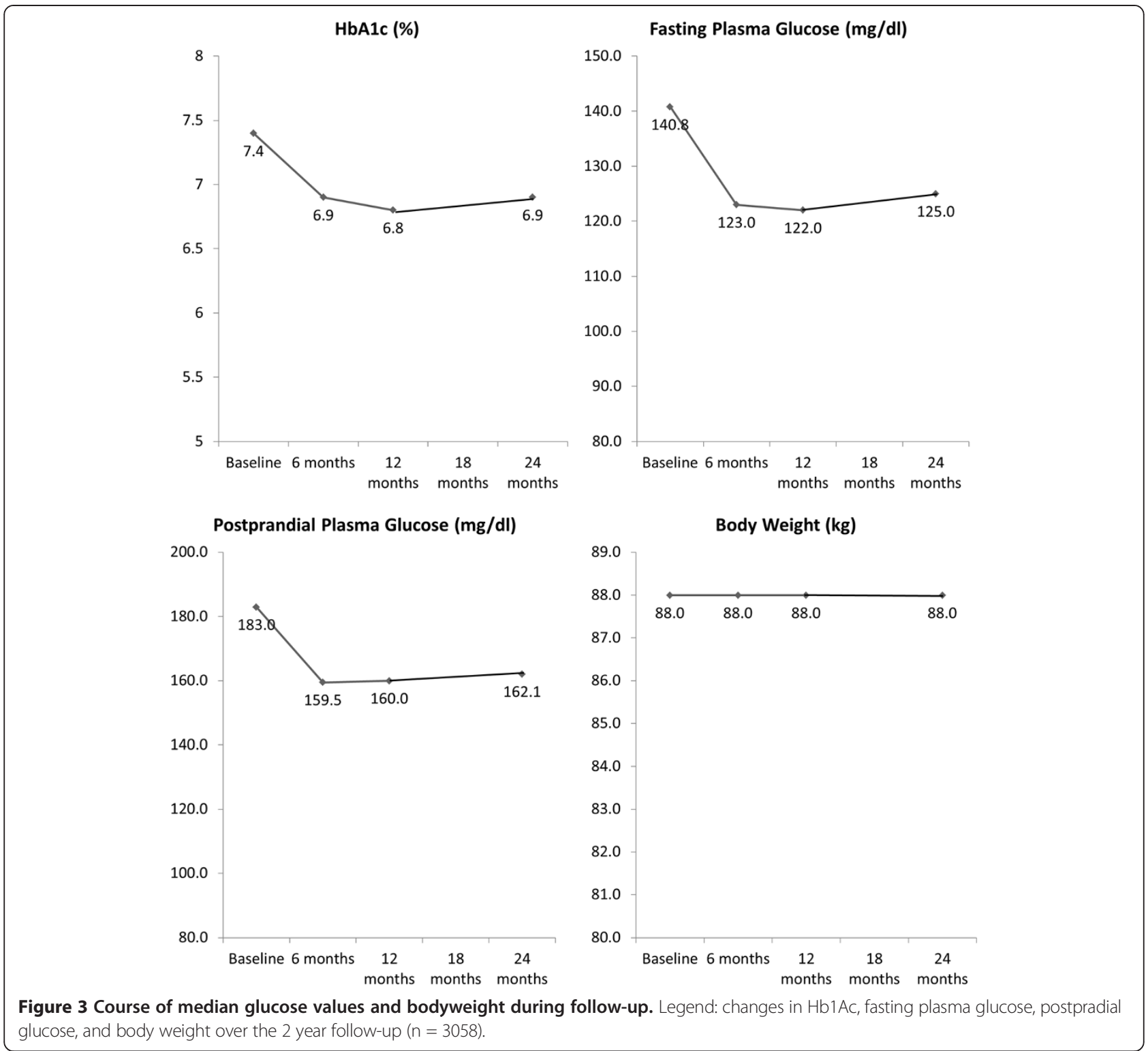

observed a consistent trend of increased macrovascular and microvascular events in patients with prior vascular disease, longer diabetes duration, and HF at baseline. Moreover, we found that predictors for a combined cardiovascular endpoint (i.e., macro-/microvascular complications, HF, and death) included age, prior vascular disease, and HF. Notably, these risk factors were also reported in the ACCORD trial, which demonstrated that patients with previous cardiovascular events or multiple cardiovascular risk factors had a higher mortality rate on undergoing intensive glucose control therapy in comparison to standard treatment [15]. The VA diabetes trial also identified prior cardiovascular events to be a predictor for primary events during intensive antidiabetic therapy [16]. The ADVANCE randomised controlled trial compared the use of gliclazide-centred intensive therapy with standard treatment for reducing HbA1c levels in type-2 diabetics with a history of vascular complications [17]. In contrast with the ACCORD study, little difference was found in the rate of death from cardiovascular causes. However, it should be noted that the specific intensive therapies administered in these two trials differed, with a higher proportion of patients in the ACCORD trial being treated with insulin. It has been suggested that this may be a factor in the increased mortality found during this latter study [18]. The ADVANCE trial also noted that nephropathy was demonstrated to be less prevalent in patients undergoing intensive therapy [17]. This is particularly interesting owing to the increased cardiovascular risk that has been demonstrated for patients displaying indications of renal disease $[19,20]$. However, in the present study, microvascular complications, in particular 
Table 2 Events and newly diagnosed co-morbidities during follow-up

\begin{tabular}{lcc}
\hline & \multicolumn{2}{c}{ Patients with a 2 year FU* } \\
\cline { 2 - 3 } & Total patients (n) & \% of those with FU \\
\hline Death & $75 / 3058$ & 2.5 \\
Macrovascular complications & $94 / 2979$ & 3.2 \\
CAD & $24 / 2979$ & 0.8 \\
Stroke/TIA & $42 / 2979$ & 1.4 \\
PAD & $37 / 2979$ & 1.2 \\
Microvascular complications & $355 / 2979$ & 11.9 \\
$\quad$ Any retinopathy & $98 / 2979$ & 3.3 \\
Any nephropathy & $3 / 2979$ & 0.1 \\
Any neuropathy & $305 / 2979$ & 10.2 \\
Amputation & $9 / 2979$ & 0.3 \\
HF & $128 / 2979$ & 4.3 \\
Non-fatal events combined & $490 / 2979$ & 18.5 \\
All events & $565 / 3058$ & 18.5 \\
\hline
\end{tabular}

Legend: *Including those that died during follow-up; CAD, coronary artery disease; TIA, transitory ischaemic attack; PAD, peripheral artery disease; $\mathrm{HF}$, heart failure; FU, follow-up.

neuropathy and retinopathy, were found to occur more frequently in particular sub-groups of patients receiving intensive therapy, with longer diabetes duration, prior vascular disease, and HF all being predictors of such events (Table 3). In the UK Prospective Diabetes Study (UKPDS) completed in 1998, overall microvascular complications were reported to be less prevalent in patients receiving intensive antidiabetic therapies based on sulfonylureainsulin, a risk which was sustained through the 10 year follow-up period [21,22]. Incidence of macrovascular events, on the other hand, was not shown to be significantly different between the two groups in the original trial period. However, at long term follow-up, there was some evidence of a lower risk in patients who had received intensive treatment.

In the present study, we demonstrated an increase in macrovascular events for those individuals with diabetes duration of greater than 5.6 years at baseline. Data obtained during the VA diabetes trial led to the hypothesis that intensive therapy might reduce cardiovascular events if initiated during the first 15 years after a diabetes diagnosis. After this point, however, the results indicated that the risk of cardiovascular complications increases [16].

This study had some limitations. The list of predictors for cardiovascular complications investigated is by no means comprehensive. By evaluating patient characteristics in more detail, it may be possible to identify further factors of interest. In addition, by design, the patients included in this study required adjustments in their treatment regimens in order to achieve glycaemic control. Thus, additional changes in treatment with the aim of reaching acceptable $\mathrm{HbAc1}$ levels during the 2 year follow-up period may have impacted the results. Finally physicians participating in this registry where chosen at random from a large database of which some declined. So there is a potential selection bias towards those more enthusiastic about treatment intensification.

\section{Conclusions}

In cases where antidiabetic monotherapy is unable to sufficiently control glucose levels in patients with type-2 diabetes, treatment needs to be intensified. Determining factors that may be predictors for the occurrence of cardiovascular complications in these patients is essential

Table 3 Multivariable adjusted predictors of events $(n=3058)$

\begin{tabular}{|c|c|c|c|c|}
\hline & $\begin{array}{l}\text { MAC/MIC/HF/Death } \\
\text { OR }(95 \% \mathrm{Cl})\end{array}$ & $\begin{array}{l}\text { MAC* OR } \\
(95 \% \mathrm{Cl})\end{array}$ & $\begin{array}{l}\text { MIC* OR } \\
(95 \% \mathrm{CI})\end{array}$ & $\begin{array}{l}\text { HF OR } \\
(95 \% \mathrm{Cl})\end{array}$ \\
\hline \multicolumn{5}{|l|}{ Patient characteristics at baseline } \\
\hline Age $\geq$ median & $1.36(1.10-1.68)$ & $1.15(0.71-1.86)$ & $1.15(0.89-1.47)$ & $2.25(1.21-4.16)$ \\
\hline Male vs. female & $1.17(0.96-1.43)$ & $1.36(0.87-2.14)$ & $1.21(0.96-1.54)$ & $0.74(0.45-1.20)$ \\
\hline $\mathrm{BMI} \geq$ median & $1.01(0.83-1.23)$ & $0.69(0.45-1.07)$ & $1.11(0.87-1.41)$ & $0.85(0.52-1.38)$ \\
\hline Diabetes duration $\geq$ median & $1.29(1.06-1.57)$ & $1.94(1.24-3.05)$ & $1.33(1.05-1.68)$ & $0.91(0.56-1.48)$ \\
\hline \multicolumn{5}{|l|}{ Laboratory values } \\
\hline $\mathrm{HbA} 1 \mathrm{c} \geq$ median & $1.12(0.90-1.39)$ & $0.92(0.57-1.46)$ & $1.29(1.00-1.66)$ & $1.14(0.66-1.96)$ \\
\hline$F P G \geq$ median & $1.09(0.89-1.35)$ & $1.00(0.63-1.59)$ & $1.18(0.92-.51)$ & $0.60(0.34-1.04)$ \\
\hline \multicolumn{5}{|l|}{ Complications } \\
\hline Vascular disease* & $1.73(1.39-2.16)$ & $2.72(1.72-4.31)$ & $1.58(1.22-2.06)$ & $1.14(0.66-1.96)$ \\
\hline $\mathrm{HF}$ & $2.78(2.10-3.68)$ & $1.97(1.13-3.43)$ & $1.53(1.07-2.18)$ & -- \\
\hline Severe hypoglycaemia & $1.24(0.59-2.62)$ & $0.44(0.06-3.38)$ & $1.88(0.85-4.14)$ & $1.27(0.35-4.60)$ \\
\hline
\end{tabular}

Legend: MAC, macrovascular complication; MIC, microvascular complication; HF, heart failure; BMI, body mass index; FPG, fasting plasma glucose. *Vascular disease includes $C A D$, stroke/TIA, and PAD; MICs include previously unknown retinopathy, nephropathy, neuropathy, and amputation; MACs include MI, stroke/TIA, and PAD (any peripheral intervention). Bold ORs $(95 \% \mathrm{Cl})$ reflect significant predictors of events. 
for improving the efficacy of clinical diabetes care. In the present study we have shown that age, prior vascular disease, and HF may be predictors of a poor outcome in patients receiving intense antidiabetic treatment. Further investigation into these factors, in addition to identification of others, should allow for treatment regimen to be based on individual patients' characteristics, potentially decreasing the incidence of adverse events.

\section{Abbreviations}

ACEi: Angiotensin-converting enzyme inhibitor; ACCORD: Action to control cardiovascular risk in diabetes; ADVANCE: Action in diabetes and vascular disease: preterax and diamicron MR controlled evaluation; ARB: Angiotensin receptor blocker; ASA: Acetylsalicylic acid; CAD: Coronary artery disease; CCB: Calcium channel blocker; DPP-4: Dipeptidylpeptidase-4; EXAMINE: Examination of cardiovascular outcomes with alogliptin versus standard of care; FPG: Fasting plasma glucose; FU: Follow-up; GEP: Good epidemiology practice; GLP: Glucagon-like peptide; HF: Heart failure; MAC: Macrovascular complication; MI: Myocardial infarction; MIC: Microvascular complication; OAD: Oral antidiabetic drug; PAD: Peripheral artery disease; SAVOR TIMI-53: Saxagliptin assessment of vascular outcomes recorded in patients with diabetes mellitus, thrombolysis in myocardial infarction 53; TIA: Transient ischaemic attack; UKPDS: UK prospective diabetes study; VA: Veteran's association.

\section{Competing interests}

Diethelm Tschöpe (DT), Peter Bramlage (PB), and Anselm K. Gitt (AKG) have received research support and honoraria for lectures from Bristol-Myers Squibb and AstraZeneca, the sponsors of the present registry. Steffen Schneider (StS) and Evelin Deeg (ED) have no competing interest to disclose.

\section{Authors' contributions}

$\mathrm{PB}, \mathrm{AKG}$, and DT were involved in the conception and design of the study. $\mathrm{StS}$ and ED were responsible for the analysis of data. PB drafted the manuscript, and all authors have revised the article for important intellectual content. All authors have approved the final version to be published.

\section{Acknowledgements}

We wish to acknowledge the support of Christiane Binz and Michael Krekler (Bristol Myers Squibb, Munich, Germany) during the setup, conduction, and evaluation of this registry. Further, we wish to acknowledge the support of Mirjam Strasser (Winicker Norimed $\mathrm{GmbH}$ ), and Sonja Frey and Benjamin Weidig (Stiftung Institut für Herzinfarktforschung). In addition, we wish to acknowledge the support of all participating physicians and patients without whom the present registry would not have been possible.

\section{Author details}

${ }^{1}$ Institut für Pharmakologie und präventive Medizin, Menzelstrasse 21, 15831 Mahlow, Germany. ${ }^{2}$ Institut für Herzinfarktforschung Ludwigshafen, Ludwigshafen, Germany. ${ }^{3}$ Herzzentrum Ludwigshafen, Medizinische Klinik B, Kardiologie, Ludwigshafen, Germany. "Stiftung "Der herzkranke Diabetiker" in der Deutschen Diabetes Stiftung, Bad Oeynhausen, Germany. ${ }^{5}$ Herz- und Diabeteszentrum Nordrhein-Westfalen in Bad Oeynhausen, Universitätsklinik der Ruhr Universität Bochum, Bad Oeynhausen, Germany.

Received: 7 November 2014 Accepted: 10 November 2014 Published: 19 November 2014

\section{References}

1. Matthaei S, Bierwirth R, Fritsche A, Gallwitz B, Haring HU, Joost HG, Kellerer M, Kloos C, Kunt T, Nauck M, Schernthaner G, Siegel E, Thienel F: Medical antihyperglycaemic treatment of type 2 diabetes mellitus: update of the evidence-based guideline of the German diabetes association. Exp Clin Endocrinol Diabetes 2009, 117(9):522-557.

2. Home P, Mant J, Diaz J, Turner C: Management of type 2 diabetes: summary of updated NICE guidance. BMJ 2008, 336(7656):1306-1308.

3. Inzucchi SE, Bergenstal RM, Buse JB, Diamant M, Ferrannini E, Nauck M, Peters AL, Tsapas A, Wender R, Matthews DR, ADA, EASD: Management of hyperglycemia in type 2 diabetes: a patient-centered approach: position statement of the american diabetes association (ADA) and the European Association for the Study of Diabetes (EASD). Diabetes Care 2012, 35(6):1364-1379.

4. Gerstein HC, Bosch J, Dagenais GR, Diaz R, Jung H, Maggioni AP, Pogue J, Probstfield J, Ramachandran A, Riddle MC, Ryden LE, Yusuf S: Basal insulin and cardiovascular and other outcomes in dysglycemia. $N$ Engl J Med 2012, 367(4):319-328.

5. Singh S, Bhat J, Wang PH: Cardiovascular effects of anti-diabetic medications in type 2 diabetes mellitus. Curr Cardiol Rep 2013, 15(1):327.

6. Ryden L, Grant PJ, Anker SD, Berne C, Cosentino F, Danchin N, Deaton C, Escaned J, Hammes HP, Huikuri H, Marre M, Marx N, Mellbin L, Ostergren J, Patrono C, Seferovic P, Uva MS, Taskinen MR, Tendera M, Tuomilehto J, Valensi P, Zamorano JL, Achenbach S, Baumgartner H, Bax JJ, Bueno H, Dean V, Deaton C, Erol C, Fagard R, et al: ESC guidelines on diabetes, pre-diabetes, and cardiovascular diseases developed in collaboration with the EASD: the task force on diabetes, pre-diabetes, and cardiovascular diseases of the european society of cardiology (ESC) and developed in collaboration with the European Association for the Study of Diabetes (EASD). Eur Heart J 2013, 34(39):3035-3087.

7. Bramlage P, Binz C, Gitt AK, Krekler M, Plate T, Deeg E, Tschope D: Diabetes treatment patterns and goal achievement in primary diabetes care (DiaRegis) - study protocol and patient characteristics at baseline. Cardiovasc Diabetol 2010, 9:53.

8. Gordon-Dseagu VL, Shelton N, Mindell J: Diabetes mellitus and mortality from all-causes, cancer, cardiovascular and respiratory disease: evidence from the health survey for England and Scottish health survey cohorts. J Diabetes Complications 2014. doi:10.1016/j.jdiacomp.2014.06.016.

9. Seshasai SR, Kaptoge S, Thompson A, Di Angelantonio E, Gao P, Sarwar N, Whincup PH, Mukamal KJ, Gillum RF, Holme I, Njolstad I, Fletcher A, Nilsson $P$, Lewington S, Collins R, Gudnason V, Thompson SG, Sattar N, Selvin E, Hu FB, Danesh J: Diabetes mellitus, fasting glucose, and risk of cause-specific death. N Engl J Med 2011, 364(9):829-841.

10. Barnett A, Allsworth J, Jameson K, Mann R: A review of the effects of antihyperglycaemic agents on body weight: the potential of incretin targeted therapies. Curr Med Res Opin 2007, 23(7):1493-1507.

11. Phung OJ, Schwartzman E, Allen RW, Engel SS, Rajpathak SN: Sulphonylureas and risk of cardiovascular disease: systematic review and meta-analysis. Diabet Med 2013, 30(10):1160-1171.

12. Scirica BM, Bhatt DL, Braunwald E, Steg PG, Davidson J, Hirshberg B, Ohman P, Frederich R, Wiviott SD, Hoffman EB, Cavender MA, Udell JA, Desai NR, Mosenzon O, McGuire DK, Ray KK, Leiter LA, Raz I, the S-TSC, Investigators: Saxagliptin and cardiovascular outcomes in patients with type 2 diabetes mellitus. N Engl J Med 2013, 369(14):1317-1326.

13. White WB, Cannon CP, Heller SR, Nissen SE, Bergenstal RM, Bakris GL, Perez AT, Fleck PR, Mehta CR, Kupfer S, Wilson C, Cushman WC, Zannad F, the El: Alogliptin after acute coronary syndrome in patients with type 2 diabetes. N Engl J Med 2013, 369(14):1327-1335.

14. Goossen K, Graber S: Longer term safety of dipeptidyl peptidase-4 inhibitors in patients with type 2 diabetes mellitus: systematic review and meta-analysis. Diabetes Obes Metab 2012, 14(12):1061-1072.

15. Gerstein HC, Miller ME, Byington RP, Goff DC Jr, Bigger JT, Buse JB, Cushman WC, Genuth S, Ismail-Beigi F, Grimm RH Jr, Probstfield JL, Simons-Morton $D G$, Friedewald WT: Effects of intensive glucose lowering in type 2 diabetes. N Engl J Med 2008, 358(24):2545-2559.

16. Duckworth WC, Abraira C, Moritz TE, Davis SN, Emanuele N, Goldman S, Hayward R, Huang GD, Marks JB, Reaven PD, Reda DJ, Warren SR, Zieve FJ: The duration of diabetes affects the response to intensive glucose control in type 2 subjects: the VA Diabetes Trial. J Diabetes Complications 2011, 25(6):355-361.

17. Patel A, MacMahon S, Chalmers J, Neal B, Billot L, Woodward M, Marre M, Cooper M, Glasziou P, Grobbee D, Hamet P, Harrap S, Heller S, Liu L, Mancia G, Mogensen CE, Pan C, Poulter N, Rodgers A, Williams B, Bompoint S, de Galan BE, Joshi R, Travert F: Intensive blood glucose control and vascular outcomes in patients with type 2 diabetes. N Engl J Med 2008, 358(24):2560-2572.

18. Home P: Safety of very tight blood glucose control in type 2 diabetes. BMJ 2008, 336(7642):458-459.

19. Gerstein HC, Mann JF, Yi Q, Zinman B, Dinneen SF, Hoogwerf B, Halle JP, Young J, Rashkow A, Joyce C, Nawaz S, Yusuf S: Albuminuria and risk of cardiovascular events, death, and heart failure in diabetic and nondiabetic individuals. Jama 2001, 286(4):421-426. 
20. Go AS, Chertow GM, Fan D, McCulloch CE, Hsu CY: Chronic kidney disease and the risks of death, cardiovascular events, and hospitalization. $N$ Engl J Med 2004, 351(13):1296-1305

21. Holman RR, Paul SK, Bethel MA, Matthews DR, Neil HA: 10-year follow-up of intensive glucose control in type 2 diabetes. N Engl J Med 2008, 359(15):1577-1589.

22. UK Prospective Diabetes Study (UKPDS) Group: Intensive blood-glucose control with sulphonylureas or insulin compared with conventional treatment and risk of complications in patients with type 2 diabetes (UKPDS 33). Lancet 1998, 352(9131):837-853.

doi:10.1186/1471-2261-14-162

Cite this article as: Bramlage et al:: Clinical course and outcomes of type-2 diabetic patients after treatment intensification for insufficient glycaemic control - results of the 2 year prospective DiaRegis follow-up. BMC Cardiovascular Disorders 2014 14:162.

\section{Submit your next manuscript to BioMed Central and take full advantage of:}

- Convenient online submission

- Thorough peer review

- No space constraints or color figure charges

- Immediate publication on acceptance

- Inclusion in PubMed, CAS, Scopus and Google Scholar

- Research which is freely available for redistribution 